\title{
La llengua occitana: caracterització i situació actual ${ }^{*}$ Xavier Lamuela
}

\section{Català i occità: un diasistema, dues llengües}

La llengua occitana, declarada oficial a Catalunya a l'Estatut de 2006 per mor de la seva presència a la Vall d'Aran, és una de les llengües europees que han conegut una història més adversa. Vehicle de l'esplendorosa lírica trobadoresca a l'Edat Mitjana, ara és una llengua parlada amb fluïdesa per poc més d'un 4\% de la població del seu domini lingüístic. L'occità és la llengua històrica d'un territori d'una extensió aproximada de 200.000 $\mathrm{km}^{2}$ que comprèn a grans trets el terç meridional de l'Estat francès, entre l'Atlàntic, els Pirineus, la Mediterrània i el nord del massís muntanyós de l'Alvèrnia, excloent-ne les zones de llengua basca i catalana i comptant-hi, fora de França, la Vall d'Aran i la part alta de les valls alpines del cantó italià, a les províncies de Coni (Cuneo) i Torí. Entre els diversos llocs on s'ha estès històricament l'occità fora d'aquesta àrea geogràfica, s'ha de mencionar el poble de La Gàrdia, de 1.556 habitants (2010, Istat), a la província italiana de Cosenza, a la regió de la Calàbria. Dins del conjunt dels grans dialectes occitans, destaca per la seva singularitat el gascó, amb la varietat aranesa, que és parlat dins del triangle format per l'Atlàntic, els Pirineus i la Garona i una mica més a l'est al cantó nord dels Pirineus. La resta del domini occità es divideix entre les varietats septentrionals, llemosí, alvernès i vivaroalpí, i les meridionals, llenguadocià i provençal.

La història de la llengua occitana, vinculada en molts aspectes a la del català, i l'afinitat

\footnotetext{
* L'elaboració d'aquest article s'ha valgut del finançament del Ministeri de Ciència i Innovació a través del projecte $\mathrm{FFI}_{2009-07635}$
}

perceptible entre aquestes dues llengües romàniques fan que sigui especialment atractiu per als catalans adquirir un cert grau de familiaritat amb l'occità. Aquesta familiaritat els obrirà les portes d'un món que, més enllà de la seva herència literària excepcional i malgrat totes les dificultats actuals, continua mostrant una vitalitat cultural considerable.

Les afinitats evolutives entre l'occità i el català en fan dues llengües molt pròximes, fins a tal punt que els primers romanistes les consideraven com una llengua única, sota el nom inadequat de provençal. S'entén millor l'origen d'aquestes afinitats si es té en compte que el català, en els tres quarts del seu territori, és una llengua de colonització sobreposada a l'àrab i al mossàrab autòctons. Si ens limitéssim a prendre en consideració l'àrea original de formació de la llengua a partir del llatí local, l'anomenada Catalunya vella, veuríem sobre el mapa una zona d'una extensió semblant a la de cada un dels grans dialectes que formen la llengua occitana; una àrea geolingüística que entraria naturalment dins d'aquest conjunt.

En la perspectiva de la caracterització lingüística i de la seva projecció històrica, podem dir que el català i els grans dialectes occitans constitueixen un dels diasistemes integrats en el conjunt de les varietats romàniques, el diasistema que Pèire Bec (1995:6) anomena occitanoromànic. Uriel Weinreich (1954:389-90) va definir el terme diasistema en el context de l'estructuralisme lingüístic i dels estudis de dialectologia; es referia a un sistema lingüístic que n'engloba dos —o mésde semblants, tenint en compte tot el que tenen en comú i la correspondència regular entre les diferències que els separen. Naturalment, aquesta definició deixa suspès el problema del grau 
d'homogeneïtat que es pot considerar adequat per a decidir que un conjunt de varietats afins formen un diasistema; l'ús que faig aquí d'aquest terme implica el reconeixement d'un grau d'afinitat estructural que permet d'agrupar les varietats romàniques en conjunts relativament uniformes $i$ que, en el cas que ens ocupa, postula un grau de diferenciació semblant, posem per cas, entre el català i el llenguadocià, per una banda, i aquest i el provençal, per una altra. Veurem més endavant quins aspectes lingüístics reforcen aquest plantejament i quins ens conviden a relativitzar-lo.

És, en tot cas, un fet conegut que, en la definició de les llengües tal com l'entenem en les nostres societats actuals, tenim en compte sobretot factors diferents dels simplement lingüístics. Si, d'una banda, existeixen testimonis medievals que identifiquen els occitanòfons i els catalanòfons — n'hi haurà prou de recordar que Dante situa la llengua d'oc a Hispània-, de l'altra, els catalans distingeixen les dues llengües des dels primers textos, fins al punt que Ramon Llull feia fer traduccions occitanes dels seus llibres amb l'objectiu de difondre's nord enllà (Badia, Santanach \& Soler 2009). Precisament l'ús que els catalans feien de l'occità medieval com a llengua de la poesia ens permet de constatar la distinció entre aquesta i la llengua emprada per a la redacció dels textos en prosa. Es pot parlar, doncs, de dues tradicions literàries i culturals diferenciades, que es van consolidar com a tals, això sí, en el context històric de divergències polítiques creixents. Si pensem en les llengües com a elements creadors d'espais distints de comunicació, constatarem que el català i l'occità són, des dels seus orígens, els fonaments de dos espais diferents, cosa que no ens priva de preconitzar la conveniència d'un acostament entre aquests dos espais, que s'hauria de vincular a una promoció eficaç de totes dues llengües. No és arriscat afirmar que, si l'occità fos utilitzat àmpliament, com el català, els parlants de l'un i de l'altre es comunicarien espontàniament utilitzant cadascú la seva pròpia llengua; de fet és això el que passa quan algú que parla correntment l'occità té relació amb catalanòfons.

\section{Diferències d'evolució fonètica entre el català i els dialectes occitans}

És habitual la pràctica de triar certs trets característics de les varietats lingüístiques per a diferenciar-les i classificar-les. Es tracta d'un procediment simplificador que cal utilitzar amb reserva perquè, si, d'una banda, ajuda a orientar-se, de l'altra, pot posar en circulació deformacions notables dels fets lingüístics.

En el cas que ens ocupa, podem començar recordant sumàriament les principals diferències fonètiques que separen el català del conjunt dels dialectes occitans en la perspectiva de l'evolució a partir del llatí (vegeu Bec 1995):

1. La conservació de la pronunciació de la $\cup$ en català, enfront de l'articulació avançada pròpia de l'occità, del francès, del francoprovençal i de les varietats més occidentals del retoromànic i del conjunt dialectal italià septentrional: CAT lluna, pruna ['u]; occ luna, pruna ['y].

2. La conservació de la o tancada de la llengua antiga en posició tònica, pronunciada com a u en occità modern: CAT raó, poma ['O]; OCC rason, poma ['u]. Cal dir, però, que el català més septentrional ha seguit la mateixa evolució que l'occità.

3. L'evolució fins a i i ui d'una part de les vocals obertes e i o del llatí tardà, diftongades en certes condicions, mentre que en la major part dels dialectes occitans donen ie(i) i ue(i): CAT llit, cuit; occ lièch / lieit / lheit, cuèch / cueit.

4. La palatalització de la L inicial i doble del llatí, que penetra dins d'una petita part del domini llenguadocià: CAT llop, castell; occ lop, castèl / castèth, però chastèlh, amb palatalització de la L doble llatina esdevinguda final, en alguns dialectes alvernesos.

5. El resultat e de la A en síllaba final àtona davant de consonant llatina: CAT cantes, cante (tercera persona del singular, en alguns dialectes), vaques; occ cantas, canta, vacas. Aquest fenomen, que afecta els plurals dels mots femenins en a àtona final, penetra dins del domini occità, concretament, en territori gascó, a la Vall d'Aran, a l'alt Comenge i a l'alta Bigorra. 


\section{Característiques fonètiques compartides pel gascó i el català}

Si, seguint el mateix procediment, mirem de caracteritzar les grans divisions dialectals de l'occità, destacaran de seguida les evolucions fonètiques antigues que distingeixen les varietats gascones. En primer lloc cal esmentar-ne tres de compartides pel gascó i el català:

1. La reducció dels grups llatins MB i ND respectivament a $\mathrm{m}$ i a $n$ : cama camba / chamba; espona $\sim$ esponda.

2. La pronunciació conservada del so [W] dels grups QU i GU: quan quand ['kan]; guarir garir.

3. L'avançament a e, oberta o tancada, de la a del diftong ai [aj]: llet / lèit lait / lach; cantaré / cantarè(i) cantarai. És un fenomen que penetra en domini llenguadocià i que reapareix en varietats occitanes del nord, probablement com a resultat d'una evolució més tardana.

\section{Particularitats fonètiques del gascó}

Són específiques del gascó les evolucions següents:

1. El pas de la F llatina a una aspiració [h]: hilh 'fill', hèr 'ferro' (vegeu el mapa de la p. 37). Aquesta aspiració s'ha perdut a la major part de la Vall d'Aran, en una part del Comenge i en altres zones de la perifèria gascona.

2. La caiguda de la N llatina entre vocals: lua 'lluna', haria 'farina'.

3. L'aparició d'una a davant de $r$ inicial de paraula: arròda 'roda'.

4. El pas de la L doble del llatí a th (pronunciat com a t o tx —o oclusiva palatal [c] — segons les paraules i els llocs) quan va quedar en posició final i a $r$ quan va quedar en posició intervocàlica: vedèth 'vedell', castèth 'castell', vederar 'vedellar', garia 'gallina'.

\section{Separació de les varietats septentrionals}

Es pren com a evolució caracteritzadora de les varietats septentrionals la palatalització de la c i de la G llatines davant de A: cantar chantar, gauta jauta 'galta'. Dins del conjunt septentrional, els dialectes vivaroalpins presenten la caiguda de la T intervocàlica llatina, generalment conservada com a $d$ en els altres dialectes: chantada chantaa, vedèl veèl. Cal dir, però, que aquesta evolució i d'altres trets propis del vivaroalpí, com ara la primera persona singular del present d'indicatiu en -o [u], també són presents a l'extrem oriental del domini occità en una zona situada al sud de la línia que delimita l'àrea de palatalització de la c i de la G llatines davant de A (Revèst 2008; Sumien 2009: 28; vegeu també el mapa).

\section{Trets fonètics que no es corresponen amb les divisions generals dels dialectes}

D'altres trets d'evolució fonètica tenen una distribució geogràfica que no coincideix amb les grans divisions dialectals:

1. La caiguda de la $N$ llatina que hauria quedat en posició final: $p a \sim$ pan, vi $\sim$ vin. Hi ha conservació de la $n$ - generalment amb pronunciació velar com la que tenim en català a la paraula sang ['san] — en la major part dels dialectes gascons i en l'extrem oriental del domini lingüístic: dialectes provençals i la majoria dels alpins; coneixen la caiguda de $n$ algunes varietats gascones $i$ alpines, el català i tot el centre occità: Ilenguadocià, llemosí, alvernès i les varietats més occidentals del vivaroalpí. Val a dir que la grafia occitana manté la $n$, muda o pronunciada segons el dialecte que s'utilitzi.

2. El pas de la / final a u semivocal [W]: abril abriu, sal sau. És un tret propi del gascó i del provençal i és present en varietats septentrionals, on també hi ha casos de conservació, de caiguda o de pas a $r$ de la / final.

3. La palatalització de la seqüència it [jt] en ch [t]] (amb diverses evolucions ulteriors): llet / lèit / lait lach; cuit / cueit / cuèit cuèch / cuech. El català, el gascó i el llenguadocià més proper conserven la seqüencia it, conservada també en una franja nord del domini occità que s'eixampla per a englobar l'alvernès i el vivaroalpí més occidental; la resta de les varietats occitanes, compreses la major part de les septentrionals, coneixen el canvi. 


\section{Taula 1 Principals evolucions fonètiques del català i dels dialectes occitans}

\begin{tabular}{|c|c|c|c|c|c|c|}
\hline $\begin{array}{l}\text { Ètim } \\
\text { o1 MEDIU }\end{array}$ & $\begin{array}{l}\text { Llemosí i Alvernès+ } \\
\text { miei / mei }\end{array}$ & $\begin{array}{l}\text { Alpí } \\
\text { miei }\end{array}$ & $\begin{array}{l}\text { Provençal } \\
\text { mieg }\end{array}$ & $\begin{array}{l}\text { Llenguadocià } \\
\text { - }\end{array}$ & $\begin{array}{l}\text { Gascó } \\
\text { miei }\end{array}$ & $\begin{array}{l}\text { Català } \\
\text { mig }\end{array}$ \\
\hline O2 LECTU & liech / lieit / leit & liech / lieit & liech & - / lièit & - & llit \\
\hline O3 OCULU & uelh & - & - & - & - & ull \\
\hline 4 осто & uech / ueit & - & uech & - / vèit & - & huit > vuit \\
\hline 5 LACTE & lach / lait & - & lach & - / lait / lèit & lèit & llet \\
\hline 06 FACTU & fach / fait & - & fach & - / fait / fèit & hèit & fet \\
\hline O7 CAUL-E /-ITTL & chaul & - & caulet & - & - & $\mathrm{col}$ \\
\hline O8 CAUSA & chausa & - & causa & - & - & cosa \\
\hline 9 RATIONE & raso(n) & rason & - & raso(n) & - / rason & raó ['o] occ ['u] \\
\hline O PLACERE & plaser & - & - & - & - / plader & plaer \\
\hline 11 CANTATA & chantada & chantaa & cantada & - & - & cantada \\
\hline 12 PUTEU & potz & - & - & - & - & $\operatorname{pou}[\mathrm{\prime} \mathrm{O}] \sim \operatorname{occ}[\mathrm{'} \mathrm{u}]$ \\
\hline 13 *VOLETIS & voletz & - / vole(tz) & - & volètz & - & voleu \\
\hline 14 AUDIRE & auvir / ausir & auvir & ausir & - & - / audir & oir (sentir) \\
\hline 15 SUDARE & suar / susar & suar & susar & - & - / sudar & $\operatorname{suar}[\mathrm{u}] \sim \operatorname{occ}[\mathrm{y}]$ \\
\hline 16 CREDERE & creire & - & - & - & créser / -d- & - creure \\
\hline 17 PEDE & pè & - & - & - & - & peu \\
\hline 18 CREDIT & crei & - & - & - & cre / cred & creu \\
\hline 19 BELLA & bèla & - & - & - & bèra & bella \\
\hline 20 CASTELLU & chasteu / -I / -Ih & chastèu / -I & castèu & castèl & castèth & castell \\
\hline 21 ANNU & an & - & - & - & - & any \\
\hline 22 CAPANNA & chabana & - & cabana & - & - & cabana / -ny- \\
\hline 23 *CUMBA & comba & - & - & - & coma & coma $\left[{ }^{\prime} \mathrm{O}\right] \sim \operatorname{occ}[\mathrm{U}]$ \\
\hline 24 SPONDA & esponda / -ò- & - & - & - & espona & espona ['o] occ ['u] \\
\hline 25 LUNA & luna & - & - & - & lua & lluna $\left.{ }^{-1} \mathrm{u}\right] \sim \operatorname{occ}[\mathrm{y}]$ \\
\hline 26 LEGE & lei & - & - & - & - & llei \\
\hline 27 QUANDO & $\mathrm{q}(\mathrm{u})$ and & - & - & - & quan & quan \\
\hline 28 QUATTUOR & $q(u) a t r e$ & - & - & - & quate & quatre \\
\hline 29 WARDON & gardar & - & - & - & guardar & guardar \\
\hline $3 O$ WARJAN & garir & - & - & - & guarir & guarir \\
\hline 31 SALE & sau / -1 & - & sau & sal & sau & sal \\
\hline 32 VITELLU & vedeu / -I / -lh & veèl / -u & vedèu & vedèl & vedèth & vedell \\
\hline 33 DIRECTU & drech / dreit & - & drech & - / dreit & dret & dret \\
\hline 34 PANE & $\mathrm{pa}(\mathrm{n})$ & pan & - & $\mathrm{pa}(\mathrm{n})$ & $-/$ pan & $\mathrm{pa}$ \\
\hline 35 VINU & vi(n) & vin & - & $v i(n)$ & $-/$ vin & vi \\
\hline 36 CANTAT & chanta & - & canta & - & - & canta \\
\hline 37 BRANCA & brancha & - & branca & - & - & branca \\
\hline 38 MUSCA & moscha & - & mosca & - & - & $\operatorname{mosca}[\mathrm{H}] \sim \operatorname{occ}[\mathrm{H}]$ \\
\hline 39 BRACA & braja / -i- & braia & braga & - & - & braga \\
\hline 40 *GAUOTA & jauta & - & gauta & - & - & gauta $>$ galta \\
\hline 41 PLAGA & plaja / -i- & plaia & plaga & - & - & plaga \\
\hline 42 PODIU & puei & - & puèg & - & puei & puig \\
\hline
\end{tabular}

Aquesta taula només presenta les evolucions que podem considerar antigues i que caracteritzen els grans dialectes occitans, sense precisar la pronunciació concreta de les formes que conté i prescindint d'algunes solucions molt localitzades; algunes lletres que s'escriuen habitualment apareixen entre parèntesis per a indicar que són mudes segons una determinada evolució dialectal: pan ['pan] pa(n) ['pa]. Com es pot veure, els resultats d'aquestes evolucions sovint divideixen les àrees geogràfiques dels diversos dialectes, cosa que s'indica amb barres inclinades. S'utilitzen guions per a indicar que es troba la mateixa evolució que en la columna anterior, prescindint de la notació dels accents, adaptada a la pràctica habitual en l'ús escrit de cada dialecte.

+ Dins del conjunt format pel llemosí i l'alvernès, les formes sense diftongació (mei 'mig', leit 'llit') i les formes amb palatalització d'una I final provinent de L doble llatina (chastèlh, vedèlh) són pròpies d'àrees particulars de dialecte alvernès. 


\section{Les grans divisions dialectals de la llengua occitana}

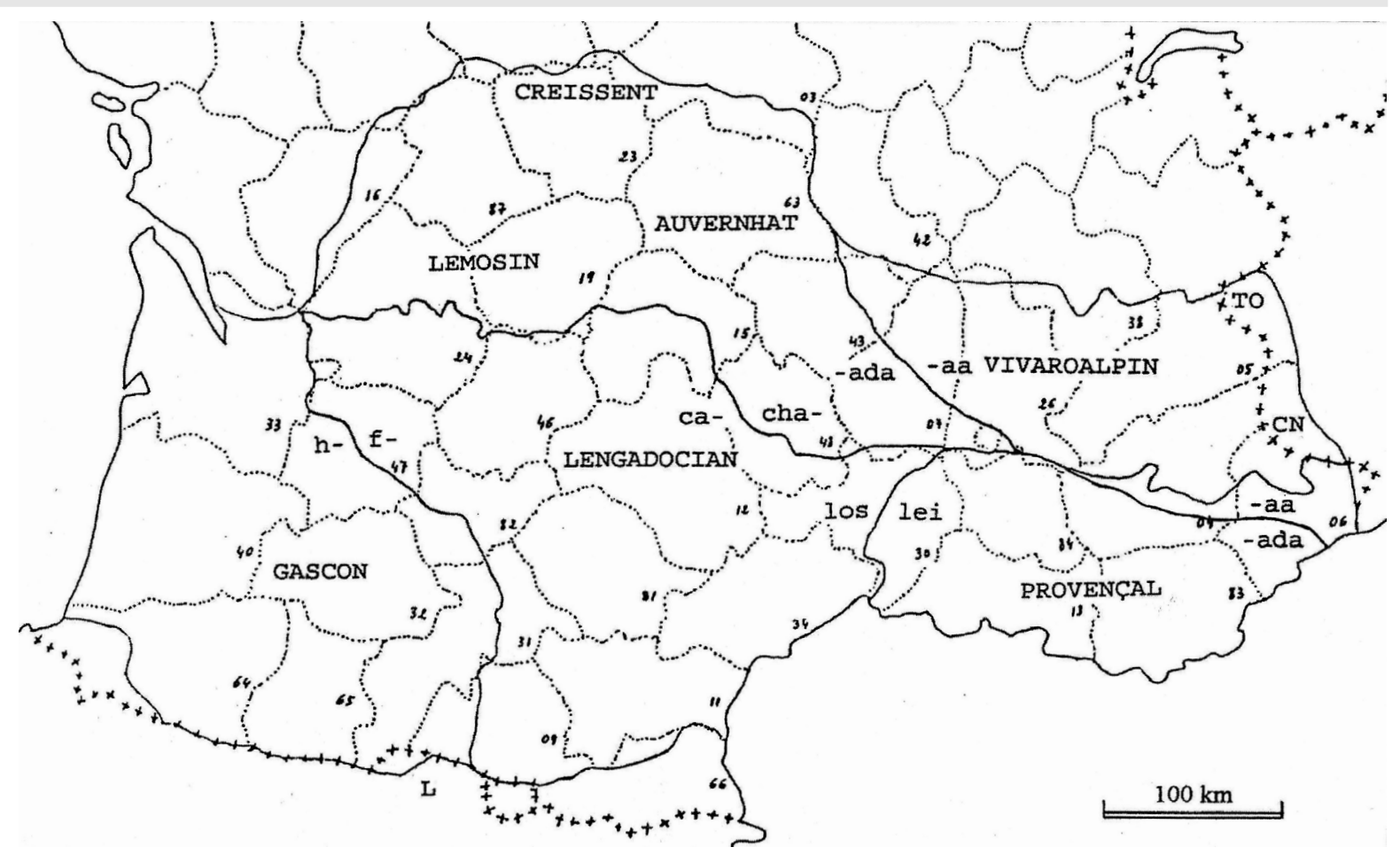

Aquest mapa ha estat elaborat a partir dels que dóna Teulat (1985: 143-47) i amb dades de Martèl (1983), Martin \& Moulin (1998) i Rohlfs (1977). Hi figuren els departaments francesos identificats pels números corresponents i la referència a la província catalana de Lleida $(\mathrm{L})$, on s'enquadra administrativament la Vall d'Aran, i a les piemonteses de Coni (CN) i Torí (TO), on es troben les valls occitanòfones de la banda italiana. Les línies de creuetes corresponen a les fronteres d'estat i les línies contínues als límits de l'occità i de determinats trets lingüístics interns.

Entre les diverses evolucions fonètiques que caracteritzen el gascó, s'ha pres com a representativa l'aspiració de la F llatina. Tot i que el llemosí i l'alvernès són dialectes ben distints, no existeix un tret, entre els que els separen, que es pugui prendre com a prou representatiu. La palatalització de c i de G davant de A (cantar chantar, gauta jauta), que s'ha pres com a tret definidor dels dialectes del nord, al Gavaldà (dept. 48, Losèra), al sud del Vivarès (dept. 7. Ardecha) i sovint més a l'est, és present en dialectes que en d'altres aspectes continuen les varietats meridionals immediates. Inversament, tal com ja he avançat, els trets propis del vivaroalpí arriben al mar a l'extrem oriental i donen lloc a una àrea dialectal vivaroalpina sense palatalització de c i de G davant de $\mathrm{A}$; entre aquests trets, destaca l'absència de $\mathrm{d}$ provinent de $\mathrm{T}$ intervocàlica llatina (chantada chantaa), que delimita el vivaroalpí a l'oest. Com a element característic que separa el provençal i el llenguadocià, s'ha pres la forma de l'article de plural ( $\mathrm{m}$. los / f. las m. i f. lei), associada al fenomen de la pèrdua de la s com a marca de plural en provençal; cal dir que al mapa s'indica només aquesta línia de separació entre els dos dialectes i es prescindeix de les altres variacions geogràfiques de l'article.

\section{Diferències en els hàbits articulatoris $\mathbf{i}$ evolucions més recents}

A les diferències dialectals relatives a evolucions fonètiques antigues, representades de manera habitual en la grafia corrent, cal afegir diferències associades a hàbits articulatoris, probablement també antics, i a evolucions fonètiques més recents però determinants en l'aspecte fònic dels dialectes actuals. Pel que fa als hàbits articulatoris, 
destaca el relaxament de les oclusives sonores en determinats contextos, especialment entre vocals, fenomen que oposa el llenguadocià i el gascó, d'una banda, al provençal i als dialectes septentrionals, de l'altra; si prenem la frase «acabava de pagar» (que en occità vol dir 'estava acabant de pagar'), observarem una pronunciació

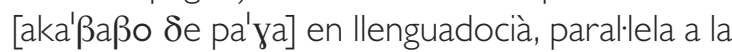
més general del català, en què només s'atura el pas de l'aire per a pronunciar les oclusives sordes, $k$ i $p$, mentre que $b$, $d$ i $g$ es pronuncien com a contínues, sense interrupció del pas de l'aire: $[\beta]$,

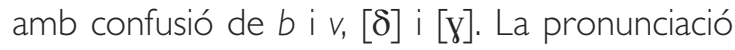
provençal [aka'bavo de pa'ga] manté el caràcter oclusiu de b, d i g i l'oposició entre b i v. Les evolucions fonètiques més recents afecten d'una manera particular la caiguda de moltes consonants finals, inclosa la s dels plurals. Aquesta caiguda de consonants és pròpia de la major part dels dialectes septentrionals (amb l'exclusió d'algunes varietats vivaroalpines) i del provençal (exceptuat el niçard); es pot observar, doncs, una certa complementarietat en la distribució geogràfica dels dos fenòmens mencionats. Cal destacar també com a evolucions particulars la presència de vocals nasals i de vocals llargues oposades a les breus en alguns dels dialectes septentrionals.

\section{Alguns trets morfosintàctics dels dialectes occitans}

De l'Edat Mitjana ençà el català i l'occità han fet una evolució divergent, menys acusada entre varietats que han quedat al mateix cantó de les fronteres polítiques; l'aranès presenta una sèrie de coincidències amb les varietats catalanes del sud de la frontera hispanofrancesa i el català septentrional és més proper a l'occità en molts aspectes. El niçard i les varietats parlades a Itàlia porten la marca de la influència italiana, deguda a la seva història política. El fet és que hi ha hagut en cada cas un procés de convergència amb les llengües dominants, molt evident quan es tracta de manlleus directes, com en el cas del lèxic de difusió més recent, però també ben real quan es tracta de convergències lèxiques o sintàctiques més complexes o menys paleses (Bihler 2001). Hi ha nombrosos exemples de lèxic tradicional que mostren aquesta mena de convergència: tant el català com l'occità coneixen el verb aturar, però el primer hi prefereix parar, anàleg de la forma corresponent de l'espanyol, mentre que el segon ha generalitzat l'ús d'arrestar (arrêter en francès); els substantius germà i germana, parallels d'hermano i hermana, han desplaçat els seus sinònims catalans frare i sor (llenguadocià fraire i sòrre), especialitzats ara en el sentit religiós; el català i l'occità antics compartien el terme malaürat, però el primer ha arraconat l'ús de malaurat, desplaçat per la forma desgraciat, calcada de l'espanyola, i el segon ha adoptat malaürós ([malej'rus] o [maly'rus]), amb un sufix que es correspon amb el de la forma francesa malheureux.

Si la comparació de textos medievals catalans i occitans pot permetre sovint de constatar una correspondència sistemàtica del seu vocabulari i de la seva organització, els textos de l'època actual presenten nombroses divergències d'una mena que es pot illustrar amb el següent fragment de Joan Bodon (1975: 18-9), que acompanyo d'una traducció catalana on hi ha marcades en cursiva les diferències sintàctiques i es donen entre claus les formes literals:

(1) La femna dobriguèt lo portal e se n'anèt sul camin. Las estelas dins lo cèl beluguejavan mai que pus. A cada vial la femna se tampava, agachava, sonava. Mas degun se vesiá pas, degun respondiá pas. La femna ne podiá pas mai de cridar. Lo freg la ganhava, se tornèt virar. Davant l'ostal se pensèt: «Sabi pas ont es passat lo meu òme mas lo vòli esperar. Veirai ben, quand tornarà!l’

'La dona va obrir el portal i se'n va anar pel \{sobre el\} camí. Les estrelles al \{dins el\} cel guspirejaven més que mai \{més que més\}. A cada corriol la dona s'aturava, mirava, cridava. Però no es veia \{pas\} ningú \{diferència d'ordre\}, ningú no responia \{pas\}. La dona ja no \{en\} podia \{pas\} més de cridar. El fred la vencia, es va tornar a girar. Davant de la casa $\{$ es\} va pensar: «No sé $\{$ pas\} on ha anat \{és passat\} el meu home però el vull esperar. Ja veuré \{bé\} què faig quan torni \{tornarà\}!ı’ 
Es pot illustrar sumàriament el comportament morfosintàctic de l'occità amb alguns trets particulars. Els dos primers presenten una extensió pròxima a les fronteres polítiques:

1. La negació de frase en la major part dels dialectes occitans i en el català del nord es fa per una partícula que se situa darrere del verb. Així, en llenguadocià tenim:

(2)

a. O sai pas 'No ho sé'

b. Vòli pas aquò 'No vull això'

En aranès, en canvi, continua fent-se la negació amb l'ús de non [nu] davant del verb, al marge del fet que, com en català, existeixin partícules posposades (pas, cap...) que afegeixen valors al sentit de la negació. En dono exemples d'Era Isla des Diamants, de Mossèn Condò (1981: 56, 51, 57):

\section{(3)}

a. Non tornaram de cinc o sies ans

'No tornarem en cinc o sis anys'

b. Ère un òme que non parlave guaire 'Era un home que no parlava gaire'

c. Non ac sabetz pas tot encara 'No ho sabeu pas tot encara'

d. Jo non i vau cap solet 'Jo no hi vaig pas sol'

Es tracta d'una situació que encara es troba en textos recents del gascó meridional de l'altra banda de la frontera, per exemple en l'obra Vita vitanta 'Vida de cada dia' de Miquèu de Camelat (1937: 62, 64):

\section{(4)}

a. Totun no'm pòdi dromir sus lo camin 'Tanmateix no puc dormir al [mig del] camí'

b. Los qui passavan no's serén avisats d'arren 'Els qui passaven no s'haurien adonat de res'

c. N'avetz pas besonh de'n parlar 'No cal pas que en parleu'

2. El cas de la collocació dels pronoms febles o clítics respecte a les formes verbals d'infinitiu presenta una situació semblant. En la major part dels dialectes occitans i en el català del nord, aquests pronoms es colloquen davant de l'infinitiu, com en francès; en una part dels dialectes occitans parlats a Itàlia i en aranès van al darrere; finalment, els dialectes gascons meridionals presenten una situació vacillant. Així, en llenguadocià:

(5)

Son venguts per los veire

'Han vingut per a veure'ls'

En aranès, seguint el text citat de Condò (1981: 52, 53):

(6)

a. Avem vengut tà shugar-te es lèrmes 'Hem vingut per a eixugar-te les llàgrimes'

b. Non serà besonh d'aucir-te

'No caldrà matar-te'

I en el text de Camelat (1937: 62):

(7)

a. Lo dia que començava de ha's espés 'El dia començava a fer-se espès [fosc]'

b. La mort [...] qu'a lèu hèit de n'escobar lo monde 'La mort ha trigat poc a escombrar-ne la gent'

3. Un tret que distingeix el català de la major part dels dialectes occitans és que en aquests els noms indefinits plurals o no comptables són introduïts sistemàticament per l'anomenat partitiu, que és, en general, la preposició de i, en algunes varietats septentrionals, com el llemosí o el gascó de més al nord, la combinació d'aquesta preposició amb l'article determinat; la resta del gascó prescindeix de l'ús del partitiu. Tenim, doncs:

(8)

a. Llenguadocià: Vòli de pan.

b. Llemosí: Vòle dau $\{\leftarrow$ de+lo\} pan.

c. Gascó central i meridional: Que voi _ pan.

d. Català: Vull _ pa. Però: De pa, sí que en vull.

4. Un tret lèxic que podem considerar d'abast gramatical i que coincideix de manera precisa 
amb la frontera lingüística entre les dues llengües és el que correspon a l'ús del verb que expressa la possessió i d'altres valors associats: aver en occità i tenir en català:

(9)

a. Avián pauc d'argent

'Tenien pocs diners'

b. Auràn lèu los libres

'Tindran els llibres aviat'

c. Ai pas enveja de lo veire

'No tinc ganes de veure'l'

d. An talent

'Tenen gana'

5. És interessant, com a fenomen característic de l'evolució més recent dels dialectes occitans, donar un cop d'ull a la formació del plural, que comporta alhora elements fonològics — les variacions en l'evolució i la pronunciació de la s-i morfològics - les distincions de nombre. Les varietats gascones i llenguadocianes mantenen en general la pronunciació de la s final, que continua sent la marca característica del plural, tot i que, depenent del context consonàntic en què apareix, en la major part dels dialectes llenguadocians pot presentar la vocalització en i [j], a part de la sonorització davant de vocal, que també coneixem en català. Els següents exemples de plurals en llenguadocià illustren aquesta variació:

(10)

a. lo prat [lu'prat] los prats [lus'prats] 'prat'

b. lo jorn [lu'dzur] los jorns [luj'dzurs] 'dia'

c. l'òme ['lome] los òmes [lu'zomes] 'home'

d. lacamba[la'kambo] lascambas[las'kambos] 'cama'

e. la gauta [la'yawto] las gautas [laj'yawtos] 'galta'

f. l'auca ['lawko] las aucas [la'zawkos] 'oca'

En dialectes alvernesos del sud (Nauton 1948), la s final del sintagma nominal es perd, però a l'interior del sintagma es manté amb variacions de la mena de les que acabem de veure, de manera que els determinants porten la marca de plural i en exemples com els anteriors és, doncs, l'article el que manté una distinció que el nom perd:
(11)

a. lo prat [lu'pra] les prats [les'pra]'

b. lo jorn [lu'dzur] les jorns [le jijdzur]

c. l'òme ['lomẹ] les òmes [lẹ'zomẹ]

d. la chamba [la'tsõbe] las chambas [las'tș̃̃be]

e. la jauta [la'dzawte] las jautas [laj'dzawte]

f. l'aucha ['lawtšne] las auchas [la'zawtšn]

En provençal s'han fixat i s'han estès sistemàticament les terminacions dels determinants (pròpies també dels adjectius qualificatius acabats en vocal anteposats al nom) que marquen el plural del grup nominal, amb neutralització de l'oposició entre el masculí i el femení i amb aparició de la s originària, afegida a la marca vocàlica i sonoritzada, només davant de vocal:

(12)

a. lo prat [lu'рьа] lei prats [lej'рьа]

b. lo jorn [lu'dzus] lei jorns [lej'dzus]

c. l'òme ['lome] leis òmes [lej'zome]

d. la camba [la'kambo] lei cambas [lej'kambo]

e. la gauta [la'gawto] lei gautas [lej'gawto]

f. l'auca ['lawko] leis aucas [lej'zawko]

En d'altres dialectes, la caiguda de la s implosiva va produir canvis en les vocals que la precedien, de tal manera que aquestes vocals han preservat la distinció de nombre sistemàticament en els determinants i parcialment en els noms i els adjectius, depenent de si acaben en vocal. Així, en llemosí la caiguda de la s implosiva va provocar l'allargament o la diftongació de les vocals:

(13)

a. lo prat [lu'prs] los prats [lu:'pra:]

b. lo jorn [lu'zu:r] los jorns [lu:'zu:r]

c. l'òme ['lo:me] los òmes [lu:'zo:'mej]

d. la chamba $\left[\mid \Lambda \Lambda_{n}^{\prime} \tilde{\Lambda}: b \Lambda\right] \sim$ las chambas [la:'s $\left.\tilde{\Lambda}^{\prime}: b a:\right]$

e. la jauta [I $\Lambda_{n}^{\prime}$ zawt $\Lambda$ ] $\sim$ las jautas [la:Zn $\Lambda W^{\prime}$ ta:]

f. l'aucha ['laws $\Lambda] \sim$ las auchas [la:zıw'sa:]

Tal com mostren alguns d'aquests exemples,

1. La transcripció [e] correspon a una e pronunciada amb l'arrel de la llengua avançada, que té un so molt pròxim al de la $i$; vegeu-ne la descripció de Nauton (1948: 23-4). 
els dialectes llemosins del nord coneixen fenòmens de desplaçament de l'accent, atret, entre altres, per les vocals llargues, que, si són contigües, poden tenir aproximadament la mateixa intensitat (vegeu Javanaud 1981, Lavalade 1986 i Dourdet 2010).

6. La distribució sobre el mapa de la marca de la primera persona singular del present d'indicatiu, generalment estesa a altres temps, dibuixa un mosaic de vocals diverses que té continuïtat tant en català com en les varietats nord-italianes i retoromàniques. Tal com sabem, en català podem trobar la marca zero de l'alguerès i de l'insular (cant), la -i septentrional, la -o ([o] o [u]) de la major part de Catalunya i del nord del País Valencià i la -e de la resta del valencià. En occità hi ha -e en llemosí, en alvernès i en una franja central a cavall dels dialectes llenguadocians i provençals (chante/ cante), -i en gascó i en la major part dels dialectes llenguadocians i provençals (canti) i -o [u] en vivaroalpí (chanto).

\section{Història i present de la llengua occitana}

L'occità medieval va ser la llengua de la poesia dels trobadors, que es va escriure en els segles XII i XIII i que va obtenir un prestigi enorme a tota l'Europa occidental: a Catalunya, la llengua de la lírica va ser molt marcada per l'occità trobadoresc fins al segle XV. La llengua occitana també va ser, durant tota l'Edat Mitjana, el vehicle d'una prosa diversa que anava des de la ficció fins als usos administratius; ja hem vist que Llull va considerar necessària la traducció de la seva obra a l'occità com a mitjà per a difondre-la. Però l'arribada gradual del poder dels reis de França als diversos indrets del domini occità va provocar la reculada de la llengua del país en l'administració i en tots els usos escrits. Al moment en què l'edicte de Villers-Cotterêts, dictat per Francesc I el 1539, imposava l'ús judicial del francès a tot el reialme, el procés d'abandonament de l'occità per a les funcions administratives ja havia avançat d'una manera decisiva. Pràcticament només el regne de Navarra, unit el 1589 a la corona france- sa en la persona d'Enric IV, va mantenir l'ús oficial del gascó fins als inicis del segle XVII (Bec 1995: 77-80). Naturalment, la penetració del francès en l'ús oral es va limitar a les classes altes, de tal manera que es donava la situació de l'ús general de l'occità en una societat en què els grups dominants eren bilingües d'occità i francès. I els segles XVI i XVII coneixen de fet una producció literària important en occità, amb noms com els de Pèir de Garròs (c. 1525-1583), Loís Belaud de la Belaudiera (1543-1588) o Pèire Godolin (1580-1649).

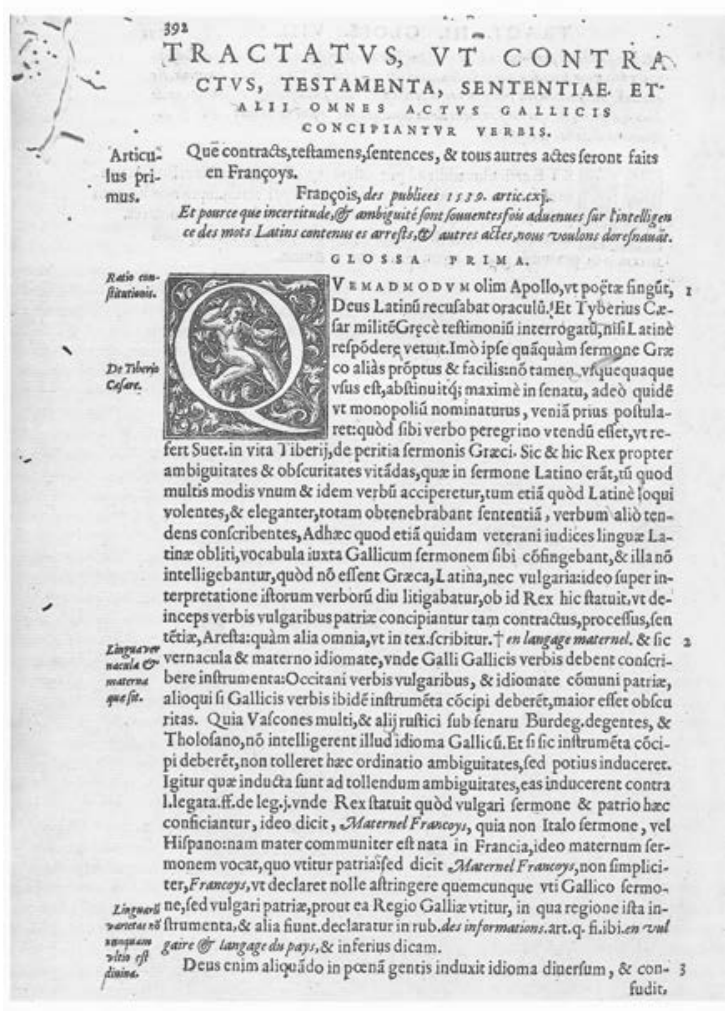

Comentari de Pierre Rebuffi sobre l'edicte de Villers-Cotterêts, promulgat per Francesc I el 1539, a l'obra Secundus Tomus Commentariorum in Constitutiones Regias Gallicas (Barcelona, Biblioteca de la Universitat de Barcelona).

Amb la revolució francesa es va escampar una ideologia burgesa d'unitat «nacional», que va portar la voluntat de difusió del francès fins a una actitud intolerant i agressiva respecte a les altres llengües parlades dins de l'Estat. Bastarà recordar el títol de l'informe d'Henri Grégoire presentat a la Convenció nacional el 1794: Rapport sur la nécessité et les moyens d'anéantir les patois et d'universaliser l'usage de la langue française. Així, al llarg 
del segle XIX, si bé es manté àmpliament la situació anterior d'estabilitat en la distribució social de les dues llengües, la substitució lingüística es veu estimulada alhora pel nacionalisme d'Estat i pel fet, nou, que es vincula a la perspectiva d'ascensió social (Sauzet 1987, 1988; Lieutard 2004). En l'ordre simbòlic, el procés de canvi lingüístic troba el seu fonament ideològic en el nacionalisme i en la creença que el francès és la llengua del progrés en el doble sentit de l'avançament collectiu i de la promoció social individual; en l'ordre pràctic, dins del context de l'ampli procés de modernització social que viu l'Europa del Vuit-cents, l'or-

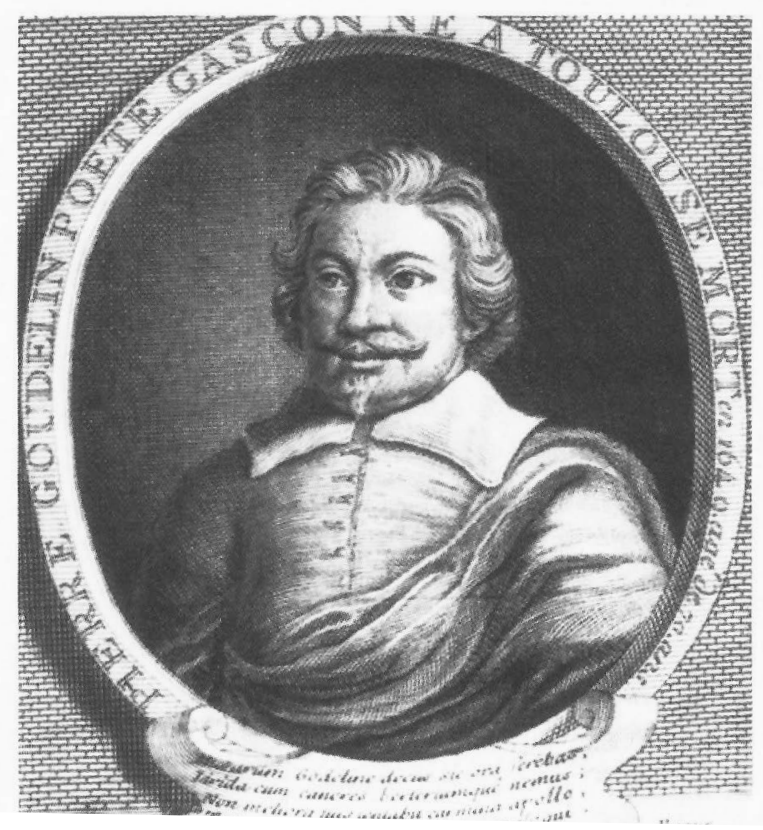

Pèire Godolin (1580-1649), poeta burgès de Tolosa que escrigué en occità (CIRDOC).

ganització i la gestió monolingües i monolingüistes de l'Estat creen les condicions que impulsen la població a la transmissió de la llengua oficial a les noves generacions. És, però, gairebé un segle més tard de la revolució que l'escola obligatòria establerta el 1881, secundada, més tard, pels mitjans de comunicació de massa, posa a l'abast del conjunt de la població el coneixement del francès. A grans trets, es pot dir que les classes altes i les classes mitjanes urbanes ja havien fet seu el francès a l'alba del segle $x x$, i que la interrupció de la transmissió familiar de l'occità es consuma entre les classes populars urbanes i a les viles mitjanes en el transcurs del primer quart d'aquest mateix segle i dins de les àrees rurals durant el segon quart. ${ }^{2}$ En aquestes darreres, es va produir un canvi sobtat del panorama sonor una vintena d'anys més tard, al moment en què la primera generació massivament monolingüe va accedir a l'edat adulta. El fet és que actualment un estranger que passi pel territori històric de la llengua occitana ben rarament arribarà a sentir-la.

Un càlcul aproximatiu de la població d'aquest territori a partir de les dades departamentals i regionals de l'INSEE per al 2008 dóna 15 milions i

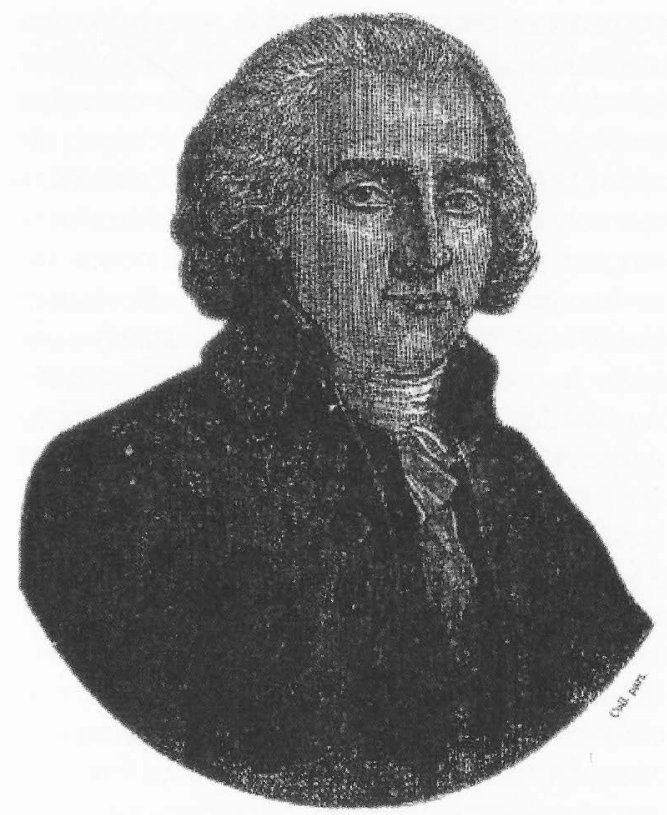

Henri Grégoire (1750-1831), que va difondre la qüestió del patois per combatre les llengües «regionals» de l'Estat francès.

mig d'habitants, un quart de la població de França. El volum de la població de la Vall d'Aran ( 9.766 habitants el 2009, segons l'Idescat) i de les Valls occitanes situades dins d'Itàlia (163.610 habitants el 2006, Allasino et al. 2007: 6) no alteren signi-

2. Són nombrosos els textos que donen testimoni de moments diversos del procés d'abandonament lingüístic. Pierre Nauton (1948: 17-20), que dedica unes pàgines representatives a descriure'l tal com es produïa a finals dels anys 40 a Saugues, població de l'Alta Alvèrnia que llavors comptava menys de 2.000 habitants ( $p .7)$, ens fa saber que els menors de vint anys encara comprenien l'occità però ja no el parlaven (p. 17). 


\section{Taula 2 - Proporció de parlants d'occità per departaments a Aquitània}

\begin{tabular}{llllll} 
Parla & Dordonya & Gironda & Landes & Olt i Garona & Pirineus Atlàntics \\
\hline Sense dificultat & $4,6 \%$ & $1,6 \%$ & $5,7 \%$ & $3,2 \%$ & $6,3 \%$ \\
Prou per a mantenir una conversa simple & $5,7 \%$ & $3,6 \%$ & $8,5 \%$ & $9,5 \%$ & $5,9 \%$
\end{tabular}

Taula 3 • Proporció de parlants d'occità per franges d'edat a Aquitània

\begin{tabular}{lllll} 
Parla & de 15 a 29 anys & de 30 a 44 & de 45 a 59 & de 60 o més \\
\hline Sense dificultat & $0,5 \%$ & $0,6 \%$ & $3,5 \%$ & $7,6 \%$ \\
Prou per a mantenir una conversa simple & $2,7 \%$ & $3,4 \%$ & $6,2 \%$ & $8,2 \%$
\end{tabular}

ficativament aquesta xifra, tenint en compte el grau d'aproximació que utilitzo. No existeixen dades globals fiables sobre el nombre de parlants de la llengua occitana, però en podem adquirir una idea prou aproximada per extrapolació dels resultats d'algunes enquestes limitades a certs territoris. La que trobo més representativa és la que va portar a terme l'empresa Teleperformance l'any 2008 a la regió d'Aquitània, que tenia llavors 3.177 .625 habitants (INSEE), comptant-hi els de l'àrea de llengua basca, exclosa de la investigació. Segons aquesta enquesta, només un $4 \%$ de la població de 15 anys o més declara que pot parlar en occità «sense dificultat, expressant tot el que vol» i un altre 5,9\% «prou per a mantenir una conversa simple» (p. 66). L'extrapolació d'aquestes proporcions al conjunt de 15 milions i mig d'habitants ens donaria unes 630.520 persones capaces de parlar amb fluïdesa i un total d'1.549.057 parlants d'occità de diversos nivells de capacitat, incloent-hi els que hi poden mantenir una conversa simple. L'extrapolació dels resultats relatius a la comprensió de l'occità donaria 2.490.947 persones que comprenen «perfectament tot el que es diu» (16\%) i 3.892.104 (25\%) que inclourien aquestes i les que entenen «fàcilment encara que se'ls escapin algunes nocions» (p. 64).

L'extrapolació dels resultats de l'enquesta realitzada per l'empresa Ifop a l'Alvèrnia l'any 2006 ens donaria xifres perceptiblement més altes. També obtindríem nombres més alts a partir de l'última enquesta existent, portada a terme l'any 2010 a la regió Migjorn-Pirineus, que comptava 2.838.228 habitants el 2008 (INSEE). De la població enquestada, de 15 anys o més, el 5,4\% declara que «parla sense dificultat, expressant tot el que vol», el 7,5\% que «parla prou per a mantenir una conversa simple», el 13\% que «comprèn perfectament tot el que es diu» i el 8,6\% que «comprèn fàcilment, encara que no ho comprengui tot» (Teleperformance 2010: 26). Però el fet que Aquitània sigui una regió més diversificada, i també que les dades d'una enquesta anterior (Média Pluriel Méditerranée 1997) coincidissin sensiblement amb les obtingudes a la part occitanòfona de la regió Llenguadoc-Rosselló (Média Pluriel Méditerranée 1998), fa pensar que les xifres que he donat deuen ser bastant a prop de la realitat. ${ }^{3}$ De fet, el desglossament per departaments dels resultats d'Aquitània al 2008 (p. 66), que varien entre l'1,6\% de parlants fluids de la Gironda, amb la ciutat de Bordeus, i el 6,3\% de l'àrea occitanòfona dels Pirineus Atlàntics, ens dóna una idea de la variabilitat de la situació seguint les zones (vegeu la Taula 2).

En tot cas, el factor més rellevant és la suspensió pràcticament acomplerta de la transmissió familiar de la llengua, que es manifesta en una retracció molt accelerada del seu coneixement i, no cal dir, del seu ús; en els resultats de l'enquesta que comento, les diferències de capacitat lingüística lligades a les franges d'edat parlen totes soles (vegeu la Taula 3, Teleperformance 2008: 66).

3. No s'entén per què Carrera (2011: 28) fa les seves extrapolacions a partir d'una enquesta de vint anys enrere (Média Pluriel Méditerranée 1991) i de fiabilitat discutida (Boyer 2001). Aquesta tria i una determinada interpretació de les dades li fan dir «que la quantitat de parlants regulars d'occità podria situar-se al voltant dels tres milions de persones»; el fet és que, segons el més optimista dels càlculs, els parlants fluids d'occità difícilment passarien de 850.000 . 
Els esforços de difusió de l'ensenyament de la llengua no arriben a alterar de manera perceptible aquesta tendència; segons Viaut (2007: 133-34), al curs 2005-2006, els escolars que van rebre alguna forma d'ensenyament d'occità a l'Acadèmia — demarcació territorial d'ensenyament — de Tolosa se situaven entorn de l'11\% del total.

La situació a la Vall d'Aran i a les valls occitanòfones d'Itàlia correspon a la història particular de cada un d'aquests territoris, determinada de manera decisiva per la dels Estats a què pertanyen. A la Vall d'Aran s'ha mantingut ininterrompuda la transmissió intergeneracional de l'occità i la situació problemàtica de la llengua és deguda a la forta immigració rebuda en condicions de subordinació lingüística. La presència de l'aranès a l'escola i a l'administració ha aconseguit d'aturar un procés de substitució lingüística altrament imparable (Lamuela 2008), però, segons l'estudi de la Secretaria de Política Lingüística i l'Idescat, el 2008 declaraven saber parlar occità només el $56,8 \%$ dels més grans de 15 anys, sobre un 78,2\% que l'entenien (Secretaria de Política Lingüística 2009: 79). Itàlia ha viscut un procés de substitució lingüística que es diferencia del francès per un retard temporal d'una o dues generacions, segons els llocs, i per una ideologia i un discurs sustentador que privilegien la idealització compensatòria dels parlars locals i la negació de l'objectiu substitutori i de la consumació objectiva del procés. ${ }^{4}$ El fet és que hi ha cessat la transmissió familiar de l'occità i que aquest es troba en una fase de regressió menys avançada que a França però igualment inexorable; mentre que el 1974 Telmon (1980) estimava la proporció de parlants en un 56,57\%, trenta anys més tard, el 2005, parlaven occità «bé o molt bé» un 34\% de la població més gran de 18 anys i el comprenien un altre 15\% (Allasino et al. 2007: 70-1).

L'occità és alhora una de les grans llengües de cultura europees i, com a conseqüència de les

4. De Agostini \& Schiavi Fachin (2011) han recollit els comentaris d'algunes persones enteses sobre una sèrie de formulacions aplicades al friülà que reflecteixen les representacions de les llengües subordinades a Itàlia. polítiques etnocides, una de les llengües que es troben en una situació social més precària. Però, malgrat una posició tan difícil, també és el vehicle d'un moviment cultural important. Al segle XIX, a la mateixa època en què es congriava el gran procés de substitució lingüística, hi va haver una renaixença de la literatura a la Provença amb l'associació literària anomenada Felibritge, fundada el 1854; hi va destacar la figura excepcional de

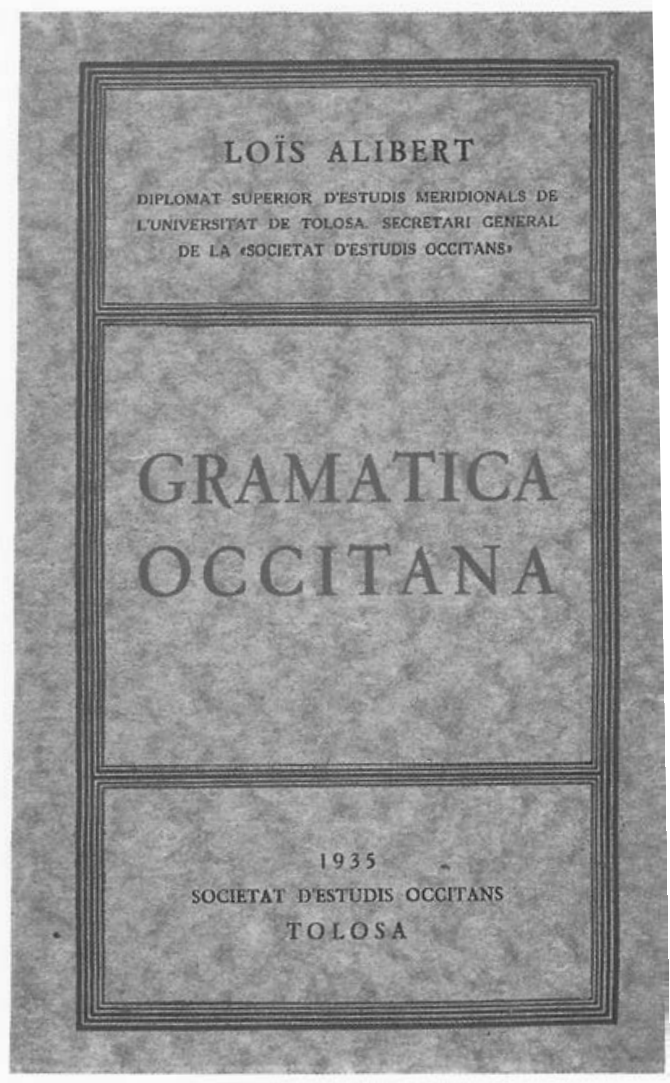

Volum primer de la Gramatica occitana segon los parlars lengadocians de Loís Alibèrt, de 1935 (Arxiu Històric de Sitges).

Frederic Mistral (1830-1914), autor d'obres com Mirèlha i Calendau i d'un diccionari que continua sent de referència obligada, Lou Tresor dóu Felibrige (1885). Aquest corrent felibrenc va tenir una projecció notable a la Gascunya, on cal anomenar l'obra de Miquèu de Camelat (1871-1962), autor de Belina i fundador de l'Escòla Gaston Febus, i de Simin Palai (1874-1965), poeta i autor d'un monumental Dictionnaire du béarnais et du gascon modernes (1932-34). La fundació el 1930 de la Societat d'Estudis Occitans, que acabaria desembocant en 
I'Institut d'Estudis Occitans (IEO), fundat el 1945, anunciava un corrent de renovació, que ha dotat l'occità modern del sistema de referències socials i culturals que constitueix la base d'una consciència renovada de la unitat lingüística i de la possibilitat d'ús de la llengua en tots els àmbits propis de la societat contemporània; les iniciatives diverses de promoció lingüística han donat Iloc a activitats professionalitzades i comencen a ferse presents en les estructures de l'administració pública. Un element clau d'aquest moviment va ser la codificació del llenguadocià, estesa després a totes les altres varietats, que va ser portada a terme per Loís Alibèrt (1884-1959), autor de la Gramatica occitana segon los parlars lengadocians
(1935) i del Dictionnaire occitan - français, publicat pòstumament el 1966. No m'entretindré ara a fer un repàs de les diverses activitats culturals que es porten a terme en occità (vegeu Boyer \& Gardy 2001 i Carrera 2011); em limitaré a recordar el nom d'alguns escriptors d'una qualitat excepcional, com Joan Bodon (1920-1975), Marcèla Delpastre (1925-1998), Bernat Manciet (1923-2005) o Max Roqueta (1908-2005), als quals es poden afegir els de Pèire Bec (nascut el 1921) i Robèrt Lafont (1923-2009), que uneixen a la seva condició d'autors literaris la de mestres d'una florida d'intellectuals, de recercadors i d'activistes culturals que mantenen viva la possibilitat d'una represa de l'ús social de la llengua occitana.

\section{Bibliografia citada}

AlıbèrT, Loís, 1935: Gramatica occitana segón los parlars lengadocians, Tolosa: Societat d'Estudis Occitans [2a ed.: Montpeller: Universitat de Montpelhièr, 1976; reimpressió: Barcelona - Tolosa: Institut d'Estudis Catalans - Institut d'Estudis Occitans, 2000].

AlıbèrT, Loís, 1966: Dictionnaire occitan - français, Tolosa: Institut d'Estudis Occitans [2a ed.: Montpeller: Universitat de Montpelhièr, 1978]

Allasino, Enrico et al. [Consuelo Ferrier, Sergio Scamuzzi, Tullio TeLmon], 2007: Le lingue del Piemonte, Torí: Regione Piemonte.

BADIA, Lola, Joan SANTANACH \& Albert SOLER, 2009: «Le rôle de l'occitan dans la production et la diffusion des œuvres de Raymond Lulle (1274-1289)», La voix occitane. Actes du VIlle Congrès de I'Association Internationale d'Études Occitanes (Bordeaux, 2005), ed. Guy Latry, vol. I, Bordeus: Presses Universitarires de Bordeaux, 369-408.

BEC, Pèire, 1995: La langue occitane, París: PUF [La 1a ed. és de 1963; n'existeix una traducció catalana: La llengua occitana, Barcelona: Edicions 62, 1977]
BIHLER, Heinrich, 2001: Die Stellung des Katalanischen zum Provenzalischen und Spanischen. Statistische Analyse katalanischer Texte aus Mittelalter und Neuzeit, Frankfurt am Main: Domus Editoria Europaea.

Bodon, Joan, 1975: Contes del Drac, Nimes: Institut d'Estudis Occitans.

BOYER, Henri, 2001: «Enquêtes quantitatives sur les images et les usages de l'occitan en Aquitaine et en Languedoc (1991-1997)», a BOYER \& GARDY (2001: 333-34)

BOyER, Henri \& Philippe GARDy (eds.), 2001: Dix siècles d'usages et d'images de l'occitan. Des troubadours à I'Internet, París: L'Harmattan.

Camelat, Miquèu de, 1937: Bitebitante. Cops de calam, Vilhèra: Escòla Gaston Febus, 1971 [cito regularitzant la grafia].

Carrera, Aitor, 2011: L'occità. Gramàtica i diccionari bàsics (occità referencial i aranès), Lleida: Pagès.

Condò, Jusèp, 1981: Era Isla des Diamants, Sant Gironç: Escolo deras Pirenéos [cito regularitzant la grafia; ara n'existeix una edició amb regularització ortogràfica: Viella: Conselh Generau d'Aran, 2006].

De Agostinı, Priscilla \& Silvana Schiavı FACHIN (eds.), 2011: Cjalant il Friûl. Pinsîrs e opinions sui lûcs comuns de lenghe furlane / Sguardi sul Friuli. Pensieri e opinioni attorno ai luoghi comuni della lingua friülana, Udin: Forum.

DOURDET, Joan-Cristòu, 2010: «Lo parlar nòrd-occitan lemosin de Montembuòu en Charanta Lemosina», Linguistica Occitana, 8, 21-47, http://www.revistadoc.org.

IDESCAT, Institut d'Estadística de Catalunya, http://www.idescat.net [consultat el 06/05/2011].

IFOP, 2006: Pratiques et représentations des langues régionales en Auvergne, presentació en diapositives, [s.l.] Ifop - Institut d'Estudis Occitans Auvèrnhe.

INSEE, Institut National de la Statistique et des Études Économiques, http://www.insee.fr [consultat el o6/05/2011].

ISTAT, Istituto Nazionale di Statistica, http://demo.istat.it [consultat el 06/06/2011] 
Javanaud, Pierre G., 1981: The Vowel System of Lemosin, Göteborg: University of Göteborg.

Lamuela, Xavier, 2008: «La Val d'Aran: Situazione sociale della lingua occitana e interventi di politica linguistica», Tutela e promozione delle minoranze linguistiche in Trentino, eds. Paola Gualtieri i Marco Viola, Trento: Provincia Autonoma di Trento, 49-66.

LaVALADE, Yves, 1986: L'accentuation occitane (haut-limousin), Llemotges: La Clau Lemosina.

LIEUTARD, Hervé, 2004: «La conversion des occitanophones à l'usage du français», Lenga e País d'Òc, 43, 1-12.

MARTÈL, Felip, 1983: «L'espandi dialect[a]u occitan alpenc: assag de descripcion», Novel Temp, 21, 4-36.

Martin, Guy, Bernard Moulin et al., 1998: Grammaire provençale et cartes lingüístiques, Ais de Provença: Comitat Sestian d'Estudis Occitans - C.R.E.O. Provença - EDISUD.

Média Pluriel MéditerRanée, 1991: Occitan. Pratiques et représentations dans la Région Languedoc-Roussillon. Sondage. Livre 1: Résultats et analyses, Montpeller.

Média Pluriel Méditerranée, 1997: Pratique et représentations de la langue occitane. Région Aquitaine, Montpeller.

Média Pluriel MéditerRanée, 1998: Pratique et représentations de la langue occitane. Région LanguedocRoussillon, Montpeller.

Mistral, Frederic, 1979: Lou Tresor dóu Felibrige ou dictionnaire provençal français, Rafèla d'Arles: Marcel Petit, 2 vols. [1a ed.: 1885].
NAUton, Pierre, 1948: Le patois de Saugues, Clermont-Ferrand: Faculté des Lettres.

PALAY, Simin, 1980: Dictionnaire du béarnais et du gascon modernes, París: Éditions du Centre National de la Recherche Scientifique [1a ed. 1932-34].

REvÈsT, Laurenç, s.d. [2008]: «La langue d'oc ou langue occitane», http:// ccocpaisnissart.chez-alice.frl ccocpn/lengadoc.htm [consultat el 14/10/2011].

Ronjat, Jules, 1941: Grammaire istorique des parlers provençaux modernes, Montpeller: Société des Langues Romanes, 4 vols. (1930, 1932, 1937, 1941) [reimpressió: Slatkine, Genève].

RoHLFs, Gerhard, 1977: Le gascon. Études de philologie pyrénéenne, Tübingen Pau: Max Niemeyer - Marrimpouey Jeune [1a ed. 1935].

SAuzet, Patric, 1987: «Delai de la diglossia. Per un modèl mimetic del contacte de lengas», Lengas, 21, 103-20.

SAUzet, Patric, 1988: «L'occitan. Langue immolée», Vingt-cinq communautés linguistiques de la France. I: Langues régionales et langues non territorialisées, ed. Geneviève Vermes, París: L'Harmattan, 208-60.

Secretaria de Política Lingüística de la Generalitat de Catalunya, 2009: «Les llengües a Catalunya: resultats de l'Enquesta d'usos lingüístics a la població 2008», Llengua i Ús, 45 , 75-91.

SeCretaria de Política Lingüística \& IDESCAT, 2009: Estadística d'usos lingüístics de la població 2008, Barcelona: Generalitat de Catalunya.
SUMIEN, Domergue, 2009: «Classificacion dei dialèctes occitans», Linguistica Occitana, 7 1-55, http://www.revistadoc.org.

Teleperformance, 2008: Résultats de l'étude sociolinguistique: «Présence, pratiques et représentations de la langue occitane en Aquitaines), Bordeus: Région Aquitaine.

Teleperformance, 2010: Résultats de l'étude sociolinguistique: «Présence, pratiques et perceptions de la langue occitane en Région Midi-Pyrénées», Tolosa: Région Midi-Pyrénées.

TELMON, Tullio, 1980: «Per un atlante delle parlate galloromanze in territorio piemontese», Bollettino dell'Atlante Linguistico Italiano, 3-4 (1979-80), 58-71.

TeULAT, Rogièr, 1985: Uèi l'occitan, [s.l.] Institut d'Estudis Occitans.

VIAUT, Alain, 2007: «L'occitan, sa diversité et son enseignement», Revue de l'Université de Moncton, numéro hors série, 131-44, http:// id.erudit.org/iderudit/017712ar [consultat el 06/05/2011].

WEINREICH, Uriel, 1954: «ls a Structural Dialectology Possible?», Word, 10.23. 388-400. 